\title{
PENGARUH PERAN PENGAWAS MENELAN OBAT (PMO) TERHADAP KEPATUHAN PENDERITA TUBERKULOSIS DALAM MENGIKUTI PROGRAM PENGOBATAN DOTS (DIRECTLY OBSERVED TREATMENT SHORTCOUSE)
}

\section{INFLUENCE of the ROLE of the SWALLOWING SUPERVISOR from FAMILY MEMBERS toward the TREATMENT COMPLIANCE among TUBERCULOSIS PATIENTS in INFLUENCING TREATMENT PROGRAM DOTS (DIRECTLY OBSERVED TREATMENT SHORTCOUSE)}

\author{
Nilna Sa'adatar Rohmah ${ }^{1 *}$, RR. Sri Ratna Rahayu², Fitri Indrawati ${ }^{3}$
}

\footnotetext{
*1Jurusan IImu Kesehatan Masyarakat, Fakultas IImu Keolahragaan, Universitas Negeri Semarang, email: nilnas.rohmah@gmail.com, Indonesia

2Jurusan IImu Kesehatan Masyarakat, Fakultas IImu Keolahragaan, Universitas Negeri Semarang, email: s.ratnarahayu@gmail.com, Indonesia

3Jurusan IImu Kesehatan Masyarakat, Fakultas IImu Keolahragaan, Universitas Negeri Semarang, email: findrati@gmail.com, Indonesia
}

\begin{abstract}
Background: Tuberculosis (TBC) treatment regimens require the introduction of PMO (Drugs Swallowing Drug) standardized on International Standards for Tuberculosis Care (ISTC) with DOTS strategy (Directly Observed Treatment Shortcouse). The goal of controlling new challenges such as TB/HIV co-infection, Multi Drug Resistance (MDR), Extensively Drug Resistance (XDR) and Loss to follow-up.

Objective: Type of cross sectional study. Population 35 PMO using saturated samples. Methods: The instruments used are questionnaires and in-depth interviews. Data analysis is univariate, bivariate and multivariate.

Results: The result of the study was the relationship between the role of PMO from family members in the supervision of taking medicine $(p=0,024)$, there was a relationship between the role of PMO from family members in drug taking assistance in Fasyankes $(p=0,002)$ and there was relationship between the influence of PMO role from family member accompaniment of sputum checks in Fasyankes $(p=0,005)$ to TBC patient compliance.

Conclusion: There is a statistical correlation between the roles of PMO from the family towards adherence to tuberculosis patients. Suggestion of research is given to related parties be reformed TBC control policy related to election criteria of PMO coming from family member in Semarang regency.
\end{abstract}

Keywords: Role PMO, Compliance, Treatment of TBC.

\section{PENDAHULUAN}

Tuberkulosis (TBC) masih merupakan penyebab utama morbiditas dan mortalitas communicable diseases setelah HIV di Indonesia. Hal ini menjadikan Indonesia sebagai negara dengan beban TBC tertinggi ke-tiga setelah India dan China, memang sebuah prestasi fantastis namun tidak bisa dibanggakan. Merujuk pada Global Tuberculosis Report WHO 2019, Indonesia merupakan negara dengan beban TBC tertinggi di dunia setelah India dan Tiongkok. Pada tahun 2018 diperkirakan terdapat 845.000 orang jatuh sakit dan 93.000 jiwa meninggal akibat TBC. Eliminasi pada tahun 2030 artinya pada tahun tersebut kasus TBC di Indonesia kurang dari 1 per 100.000 penduduk. ${ }^{1}$

Berdasarkan laporan global TBC dari WHO (World Health Organization), bahwa 
lebih dari 500.000 orang terkena penyakit TBC diluar estimasi sebelumnya dan 9 juta orang telah terkena TBC pada tahun 2013 yang menyebabkan 1,5 juta orang meninggal, termasuk 360.000 orang terinfeksi HIV dan diperkirakan terdapat 480.000 kasus baru yang mengalami XDR (Extensively Drug Resistence) TB. ${ }^{2}$ Penderita MDR akan menularkan kasus MDR baru dengan adanya penderita "TBC laten" dimana tubuh terinfeksi kuman TBC tapi tidak ada gejala atau manifestasi TBC. Penderita TB laten ini sebagian besar tidak tahu dan tidak merasa sakit sehingga tidak minum obat, sementara bakteri M.tb akan tetap aktif dan berkembang. ${ }^{3}$

Hakikatnya ketaatan pasien merupakan faktor kunci keberhasilan pengobatan. Salah satu panduan dari DOTS (Directly Observed Treatment Shortcouse) adalah panduan OAT (Obat Anti Tuberkulosis) jangka pendek dengan pengawasan langsung. Keadaan yang menjamin keteraturan pengobatan diperlukan adanya pengiringan PMO (Pengawas Menelan Obat) untuk menjamin keteraturan dan kepatuhan pengobatan penderita dengan standar pelayanan yang mengacu pada International Standart for Tuberculosis Care (ISTC) bertujuan mengendalikan tantangan baru yang ditimbulkan penyakit TBC seperti ko-infeksi TB/HIV, TBC yang resisten obat baik MDR atau XDR, Total DR (Total Drug Resistence) serta pencegahan dalam terjadinya penderita mengalami putus berobat (Loss to followup). ${ }^{4}$

Sejatinya, penderita TBC perlu diawasi karena pengobatan TBC cukup lama yaitu minimal 6 bulan yang kebanyakan penderita menjadi bosan, selain itu biasanya penderita TBC setelah minum obat 2-3 minggu sudah merasa sehat, hal ini yang menjadikan Loss to follow-up pada penderita TBC. ${ }^{5}$

Berdasarkan laporan WHO, Indonesia memiliki angka prevalensi TBC pada tahun 2014 sebesar 272 per 100.000 penduduk dan angka insiden sebesar 183 per 100.000 penduduk serta angka kematian akibat TBC diperkirakan mencapai 25 per 100.000 penduduk. Kasus MDR di Indonesia pada tahun 2013 berjumlah 1.094 kasus per 100.000 penduduk, tahun 20141.752 kasus per 100.000 penduduk dan tahun 20151860 kasus per 100.000 penduduk, dimana terjadi peningkatan setiap tahunnya pada kasus MDR di Indonesia. ${ }^{2}$ Kasus MDR di Jawa Tengah pada tahun 2013 berjumlah 106 kasus per 100.000 penduduk, tahun 2014 berjumlah 144 kasus per 100.000 penduduk dan tahun 2015 berjumlah 148 kasus per 100.000 penduduk. $^{6}$ Kasus MDR di Kabupaten Semarang sendiri, berjumlah 3 kasus dimana ada 1 kasus per 100.000 penduduk yang mengalami mortalitas. ${ }^{7}$

Berdasarkan penelitian yang dilakukan Yoisangadji dkk, ${ }^{8}$ di Puskesmas Sario Kota Manado, hubungan PMO dari pihak keluarga dengan kepatuhan minum obat menunjukkan $p$ value $=0,001$. Penelitian 
oleh Sidy ${ }^{4}$ menunjukkan hasil adanya hubungan antara peran pendampingan berobat ulang ke puskesmas oleh PMO dari anggota keluarga memberikan pengaruh terbesar terhadap kepatuhan pengobatan penderita TBC ( $p$-value 0,000$)$.

Prevalensi penderita TBC tertinggi di Kabupaten Semarang berdasarkan data dari Dinas Kesehatan Kabupaten Semarang di Puskesmas Pringapus dengan jumlah 84 kasus per 100.000 penduduk dan dan diketahui dari data rekam medis di Puskesmas Pringapus jumlah kejadian TBC pada tahun 2014 dengan BTA+ 15 kasus per 100.000 penduduk, tahun 2015 BTA +20 kasus per 100.000 penduduk dan tahun 2016 BTA+ 35 kasus per 100.000 penduduk. $^{9}$ Berdasarkan survei pendahuluan yang di lakukan oleh peneliti di Puskesmas Pringapus penderita TBC ada yang tidak memiliki PMO dikarenakan keluarga sibuk dengan pekerjaannya sendiri dan menganggap pasien sudah bisa mengurus dirinya sendiri, serta berdasarkan laporan dari Dinas Kesehatan Kabupaten Semarang 2016 terdapat 1 kasus drop out di Puskesmas Pringapus. ${ }^{7}$

Melihat dari kondisi tersebut yang menyatakan selalu ada kenaikan kasus TBC setiap tahun dan ada pasien yang tidak memiliki PMO di Puskesmas Pringapus maka peneliti tertarik meneliti "Pengaruh Peran PMO dari Anggota Keluarga Terhadap Kepatuhan Pengobatan Penderita TBC".
Setelah diketahui hasil penelitian tersebut, diharapkan upaya pengendalian kasus XDR, MDR, Total DR dan pencegahan dalam terjadinya loss to follow up pada penderita TBC serta dampak yang tidak diinginkan lainnya dapat tercapai, hingga pada akhirnya akan dapat meningkatkan angka kesembuhan penderita TBC, sehingga dapat mencanangkan menuju dunia bebas TBC tahun 2030 yang menjadi salah satu target SDGs (Sustainable Development Goals).

\section{BAHAN DAN CARA PENELITIAN}

Jenis penelitian ini adalah penelitian observasional dengan menggunakan studi analitik. Rancangan penelitian yang digunakan yaitu cross sectional dilengkapi dengan wawancara mendalam. Penelitian dilaksanakan pada bulan Juni 2017 di Puskesmas Pringapus Kabupaten Semarang.

Populasi dalam penelitian ini adalah semua PMO dari anggota keluarga yang tercatat di Puskesmas Pringapus pada bulan Januari 2016 - Desember 2016, yaitu sejumlah 35 PMO. Sampel dalam penelitian ini menggunakan sampel jenuh yaitu semua PMO dari anggota keluarga yang tercatat di Puskesmas Pringapus pada bulan Januari 2016 - Desember 2016 yaitu sejumlah 35 PMO. Instrumen penelitian menggunakan kuesioner. Teknik pengambilan data dilakukan dengan wawancara dan dokumentasi. 


\section{HASIL DAN PEMBAHASAN}

Tabel 1. Rekapitulasi Faktor yang berhubungan dengan Kepatuhan Pengobatan Penderita TBC di Puskesmas Pringapus

\begin{tabular}{llcc}
\hline \multicolumn{1}{c}{ Variabel Bebas } & p value & RP & $\mathbf{9 5 \% ~ C l}$ \\
\hline $\begin{array}{l}\text { Pengawasan dalam Minum Obat: } \\
\text { Hanya Mengingatkan }\end{array}$ & $0,024^{*}$ & 20,250 & $1,671-245,444$ \\
$\begin{array}{l}\text { Melihat Langsung Saat Minum } \\
\text { Obat }\end{array}$ & & & \\
$\begin{array}{l}\text { Pendampigan Pengambilan Obat di } \\
\text { Fasyankes: }\end{array}$ & $0,002^{*}$ & 15,000 & $2,130-105,618$ \\
Tidak Melakukan Pendampingan & & & \\
Melakukan Pendampingan & & 11,500 & $1,714-77,117$ \\
$\begin{array}{l}\text { Pendampingan Cek Ulang Dahak di } \\
\text { Fasyankes: } \\
\text { Tidak Melakukan Pendampingan } \\
\text { Melakukan Pendampingan }\end{array}$ & $0,005^{*}$ & & \\
\hline
\end{tabular}

$\left(^{*}\right)=p$ value $<0,05$ menunjukan bahwa ada hubungan antara variabel bebas dan variabel terikat Sumber: Data Primer, 2017.

Penderita TBC yang patuh ketika PMO melihat langsung saat penderita minum obat sebesar 96,4\%. Hasil uji Chi-square diperoleh nilai $p$-value sebesar 0,024 $(p<0,05)$, maka Ho ditolak yang artinya ada hubungan antara pengawasan minum obat dengan kepatuhan pengobatan penderita TBC.

Nilai RP sebesar 20,250 dengan nilai rentang Cl 95\% sebesar 1,671-245,444 (tidak melewati angka 1) yang berarti bahwa PMO yang mengingatkan dan melakukan pengawasan dalam minum secara langsung 20,3 kali lebih berpengaruh terhadap kepatuhan pengobatan penderita TBC daripada $\mathrm{PMO}$ yang hanya mengingatkan minum obat.

Variabel pendampingan $\mathrm{PMO}$ saat penderita TBC mengambil obat di Fasyankes, penderita TBC yang patuh ketika PMO melakukan pendampingan saat pengambilan obat di Fasyankes 68,6\%. Hasil uji Chi-square diperoleh nilai p-value sebesar $0,002(p<0,05)$, maka Ho ditolak yang artinya ada hubungan antara pengawasan minum obat dengan kepatuhan pengobatan penderita TBC.

Nilai RP sebesar 15,000 dengan nilai rentang Cl 95\% sebesar 2,130-105,618 (tidak melewati angka 1) berarti bahwa responden yang melakukan pendampingan ketika penderita TBC mengambil obat di Fasyankes 15 kali lebih berpengaruh terhadap kepatuhan pengobatan penderita TBC daripada yang tidak melakukan pendampingan ketika penderita TBC mengambil obat di Fasyankes.

Penderita TBC patuh ketika PMO melakukan pendampingan saat cek ulang dahak di Fasyankes sebesar 65,7\%. Hasil uji Chi-square diperoleh nilai $p$-value sebesar $0,005(p<0,05)$, maka Ho ditolak yang artinya ada hubungan antara pengawasan minum obat dengan kepatuhan pengobatan 
penderita TBC. Nilai RP sebesar 11,500 dengan nilai rentang $\mathrm{Cl} 95 \%$ sebesar 1,71477,11 (tidak melewati angka 1) berarti responden yang melakukan pendampingan ketika penderita TBC cek ulang dahak di Fasyankes, 11,5 kali lebih berpengaruh terhadap kepatuhan pengobatan penderita TBC daripada yang tidak melakukan pendampingan ketika penderita TBC cek ulang dahak di Fasyankes.

Semua variabel memiliki nilai $p<0,25$ sehingga dapat dilakukan uji regresi logistik. Setelah dilakukan analisis multivariat pada variabel-variabel tersebut, didapatkan hasil sebagai berikut:

Tabel 2. Hasil Pengujian Regresi Binary Logistic

\begin{tabular}{llll}
\hline \multicolumn{1}{c}{ Variabel } & Wald & $\boldsymbol{p}$ value & $\mathbf{9 5 \%} \mathbf{~ C l}$ \\
\hline $\begin{array}{l}\text { Pendampingan } \\
\text { pengambilan obat } \\
\text { di Fasyankes }\end{array}$ & 7,395 & 0,007 & $0,009-$ \\
\hline
\end{tabular}

Sumber: Data Primer, 2017.

$$
\text { Variabel yang paling dominan }
$$

terhadap kepatuhan pengobatan penderita TBC adalah peran PMO ketika melakukan pendampingan pengambilan obat di Fasyankes. Penderita TBC perlu mendapatkan pengawasan langsung agar minum obat secara teratur sampai sembuh. Orang yang mengawasi penderita TBC dikenal dengan istilah pengawas menelan obat $(\mathrm{PMO})^{10}$. Penderita TBC yang teratur melakukan pengobatan karena berkeinginan untuk sembuh, hal ini juga didukung adanya peran dari keluarga sebagai PMO yang selalu mengontrol pengobatan penderita TBC
Hasil penelitian tentang peran PMO dari anggota keluarga dalam pengawasan minum obat penderita TBC yang mengingatkan dan melihat langsung saat penderita minum obat sebesar 27 responden $(77,1 \%)$. Distribusi ini sesuai dengan hasil penelitian Firdaus ${ }^{11}$ yaitu bahwa peran PMO yang berpengaruh terhadap keberhasilan pengobatan sebanyak 19 responden $(59, \%)$ dan sejalan juga dengan hasil penelitian Yoisangaji $^{8}$ hubungan PMO dengan kepatuhan minum obat menunjukkan nilai $p$ value 0,004 .

Hasil analisis multivariat menunjukkan peran PMO dari anggota keluarga dalam pengawasan minum obat mempunyai pengaruh dalam kepatuhan minum obat penderita TBC dengan nilai $p$-value $=0,307$ dan PMO dari anggota keluarga yang melakukan peran sebagai PMO penderita TBC dengan melihat langsung ketika penderita minum obat sampai tertelan di mulut memiliki kecenderungan 20,250 kali lebih besar berpengaruh terhadap kepatuhan pengobatan penderita TBC.

Hasil penelitian ini sejalan dengan beberapa penelitian yang menyatakan PMO dari anggota keluarga terbukti mampu memberikan pengaruh terhadap kepatuhan pengobatan penderita TBC yaitu hasil penelitian Yoisangaji ${ }^{8}$ dimana $p$-value 0,004 dan hasil penelitian dengan Sidy ${ }^{7}$ dimana $p$ value 0,000 , sebab keluarga menciptakan iklim yang lebih nyaman bagi penderita sendiri ${ }^{12}$. 
Hasil diatas juga sesuai dengan pedoman nasional penanggulangan TBC Kementrian Kesehatan $\mathrm{RI}^{13}$ yaitu $\mathrm{PMO}$ telah mengawasi dan memantau penderita TBC dengan baik. Dukungan PMO dari anggota keluarga merupakan dukungan yang memberikan pertolongan praktis terhadap kegiatan pemenuhan dan pemeliharaan kesehatan keluarga. Didukung oleh kedekatan distribusi tempat tinggal pasien yang tinggal serumah sebanyak 31 responden $(88,6 \%)$ yang memberikan kemudahan oleh PMO dalam mengawasi secara langsung penderita TBC. Hal ini dikemukakan oleh Setiadi ${ }^{14}$ bahwa salah satu dukungan keluarga terhadap anggotanya merupakan dukungan instrumental praktis dan konkrit dalam hal kebutuhan makan dan minum, istirahat dan terhindarnya penderita dari kelelahan.

Berdasarkan hasil wawancara mendalam pada peran PMO dari anggota keluarga dalam pengawasan minum obat penderita TBC di wilayah Puskesmas Pringapus cukup baik. PMO sering mengingatkan dan melihat langsung penderita TBC saat minum obat, tidak jarang pula PMO juga menghitung sisa obat penderita TBC serta penderita sampai ditunggu benar-benar minum obat, jika penderita belum minum obat, PMO tidak berangkat bekerja. Apabila obat hampir habis $\mathrm{PMO}$ juga mengingatkan penderita atau PMO sendiri yang menghubungi pihak puskesmas pemegang TBC untuk melakukan perjanjian dalam pengambilan obat. Hal ini juga didukung pula pada penderita TBC yang rajin dalam minum obat dengan adanya berbagai cara dalam mengingat waktunya minum obat. Selain PMO, alarm juga sebagai pengingat penderita saat waktunya minum obat. Hal ini karena ada dorongan dalam diri penderita ingin segera sembuh dan tidak ingin menularkan penyakitnya ke orang lain, khususnya pada keluarganya.

Pemegang TBC di Puskesmas Pringapus juga membuka SMS (Short Message Service) selama 24 jam, jika ada keluhan penderita TBC atas efek samping obat atau atas penyakit yang diderita. Selama dalam melakukan tugasnya yaitu mendampingi dan mengawasi penderita, PMO bisa melakukan konsultasi penuh dengan pemegang TBC di Puskesmas Pringapus. Hal ini juga tidak menutup kemungkinan penderita untuk berkonsultasi pada pemegang TBC di Puskesmas Pringapus. Hal ini sesuai dengan teori yang menyatakan bahwa terdapat hubungan yang saling mendukung antar pelayanan kesehatan dengan kepatuhan minum obat dan tidak kalah pentingnya keyakinan pasien untuk sembuh Pare, dkk. ${ }^{15}$

Pendampingan saat penderita TBC melakukan pengambilan obat di Fasyankes merupakan salah satu tugas dari PMO karena sejatinya PMO juga berperan menemani penderita TBC untuk mengambil perbekalan obat dan pemeriksaan ulang dahak ke Fasyankes sesuai jadwal yang 
ditentukan $\mathrm{PPTI}^{5}$. Hasil penelitian tentang peran PMO dari anggota keluarga dalam pendampingan pengambilan obat penderita TBC di Fasyankes sebesar 26 responden (74,3\%). PMO dari anggota keluarga yang melakukan pendampingan ketika penderita TBC mengambil obat di Fasyankes memiliki kecenderungan 15,000 kali lebih besar berpengaruh terhadap kepatuhan pengobatan penderita TBC jika dibandingkan dengan PMO yang tidak melakukan pendampingan ketika penderita TBC mengambil obat di Fasyankes.

Sejatinya, PMO dari anggota keluarga melakukan pendampingan saat penderita TBC melakukan pengambilan obat di Fasyankes, tetapi ada 10 responden yang tidak mendampingi penderita saat mengambil obat di Fasyankes. Alasan yang paling banyak diutarakan karena adanya pekerjaan yang tidak bisa ditinggal, sehingga tugas PMO digantikan oleh pihak keluarga yang lain. Penderita TBC juga ada yang melakukan pengambilan obat sendiri di Fasyankes, karena adanya motivasi yang tinggi pada dirinya untuk sembuh itu merupakan tanggungjawab pada diri penderita dan didukung oleh keinginan penderita yang melakukan preventif adanya penularan penyakit yang dideritanya.

Usaha dalam pencarian pengobatan beberapa keluarga sudah menunjukkan beberapa partisipasi langsung berupa merujuk penderita TBC ke Puskesmas maupun ke pelayanan kesehatan lainnya, guna mendapat pemeriksaan dan pengobatan. Hasil ini sesuai dengan penelitian Limbu \& Marni ${ }^{16}$ bahwa ada beberapa keluarga yang sudah dapat menunjukkan partisipasi langsung untuk membawa penderita ke Fasyankes.

Hasil pendukung dari keluarga PMO dalam pendampingan penderita TBC saat pengambilan obat ke Fasyankes di wilayah Puskesmas Pringapus menyatakan PMO mendampingi ketika pengambilan obat ke Fasyankes, tetapi jika bekerja nanti ya bersifat insidental atau situasional. Penelitian ini sesuai dengan penelitian Dubale $\mathrm{dkk}^{17}$ bahwa pengawasan TBC tidak terencana. Anggota keluarga PMO yaitu penderita itu sendiri juga menyatakan bahwa harus memotivasi diri sendiri jika memang sembuh dan tidak ingin penyakit yang dideritanya menular ke orang lain.

Hasil pendukung dari tenaga kesehatan selaku pemegang program TBC di wilayah Puskesmas Pringapus menyatakan bahwa ketika pengambilan obat selalu adanya doktrin, apalagi kalau waktu pertama kali ketemu adanya dua pilihan yang disampaikan ke penderita TBC yaitu "ingin sembuh atau ingin tambah parah". Jika memang obatnya habis selalu menginformasikan terlebih dahulu via SMS guna untuk melakukan kesepakatan waktu dalam mengambil perbekalan obat. Hasil penelitian ini setara dengan Khachadourian $\mathrm{dkk}^{18}$ dimana petugas kesehatan menginformasikan terlebih dahulu via SMS 
ketika penderita ingin kontrol maupun pengambilan obat di Fasyankes. Penderita TBC maupun PMO yang mendapatkan edukasi maupun konseling dari tenaga kesehatan juga sesuai dengan hasil penelitian M'Ilmunya J.M., dkk ${ }^{19}$.

Berdasarkan $\mathrm{WHO}^{21}$ pada buku pedoman pengobatan TBC, semua pasien TBC melakukan cek ulang dahak ketika sudah melakukan masa pengobatan selama 2 bulan. Demikian berdasarkan dari Kemenkes $\mathrm{RI}^{20}$ pasien TBC yang positif melakukan pemeriksaan ulang dahak selanjutnya pada bulan ke-5. Apabila hasilnya negatif, pengobatan dilanjutkan hingga seluruh dosis pengobatan selesai dan dilakukan pemeriksaan ulang dahak kembali pada akhir pengobatan. Ini merupakan salah satu tugas dari PMO yang juga berperan menemani penderita TBC untuk mengambil perbekalan obat dan pemeriksaan ulang dahak ke Fasyankes sesuai jadwal yang ditentukan PPTI. ${ }^{5}$

Hasil penelitian tentang peran PMO dari anggota keluarga dalam pendampingan cek ulang dahak penderita TBC di Fasyankes sebesar 25 responden $(71,4 \%)$ dan diperoleh nilai $p$-value $0,005<0,05$. Hal ini menandakan adanya hubungan yang bermakna antara variabel peran PMO pendampingan cek ulang dahak penderita TBC dengan kepatuhan pengobatan penderita TBC. Hasil lebih lanjut dengan penilaian RP (Ratio Prevalens) 11,500 berarti hasil penelitian ini membuktikan bahwa PMO yang melakukan pendampingan ketika penderita cek ulang dahak ke Fasyankes.

kategori baik memiliki kecenderungan 11,500 kali lebih besar berpengaruh terhadap kepatuhan pengobatan penderita TBC. Hasil pengukuran RP ini memperkuat hasil penelitian Sidi ${ }^{4}$ dimana pendampingan PMO saat penderita cek ulang dahak ke Fasyankes memiliki OR 16,017 yang berarti PMO yang melakukan pendampingan ketika penderita cek ulang dahak ke Fasyankes kategori baik memiliki kecenderungan 16,017 kali lebih besar berpengaruh terhadap kepatuhan pengobatan penderita TBC.

Berdasarkan hasil wawancara mendalam pada peran PMO dari anggota keluarga dalam pendampingan penderita TBC saat cek ulang dahak ke Fasyankes di wilayah Puskesmas Pringapus cukup baik. Penyataan PMO dari anggota keluarga yaitu dilakukannya cek dahak di bagian laboratorium dan dilakukan rongen yang bertempat di BKPM (Balai Kesehatan Patu Mayarakat) Ambarawa. Hal ini dikarenakan adanya rujukan Puskesmas Pringapus serta rujukan dari bidan setempat. Beberapa penderita TBC sengaja dirujuk karena adanya renovasi Puskesmas Pringapus, setelah renovasi selesai pengecekan dahak kembali dilakukan ke Puskesmas Pringapus karena mengingat biaya yang dikeluarkan oleh penderita TBC, hal ini sesuai dengan strategi nasional TBC yaitu untuk mencapai tingkat kesembuhan yang tinggi pengobatan pasien TBC membutuhkan penggunaan obat 
TBC secara rasional oleh tenaga kesehatan dan dukungan yang memadai dari berbagai pihak terhadap pasien TBC dan PMO salah satunya yaitu dengan meminimalkan opportunity costs dan mempermudah penderita maupun PMO terhadap akses pelayanan kesehatan yang telah tersedia Kemenkes $\mathrm{RI}^{22}$.

Wawancara mendalam yang
dilakukan dengan PMO, yaitu
mengatakan cek ulang dahak lagi di BKPM. Hal ini juga dilengkapi pendukung dari keluarga PMO yang juga sebagai penderita TBC bahwa PMO melaksanakan tugasnya dengan baik, mengantar penderita TBC pemeriksaan dahak, cek ulang dahak sampai dinyatakan dahaknya bersih dari Mtbc.

Hasil pendukung dari tenaga kesehatan untuk peran PMO dalam pendampingan penderita TBC saat cek ulang dahak ke Fasyankes di wilayah Puskesmas Pringapus tidak bisa diperketat, karena jika terlalu ketat harus PMO yang mengantar, takutnya penderita TBC malas dalam berobat. Petugas kesehatan menyatakan bahwa PMO itu punya kesibukan, punya tanggungan dalam hal keluarga, mencari nafkah. Akhirnya yang mengantar juga bergantian, siapa yang bisa jadi bersifat insidental.

\section{KESIMPULAN}

PMO dari anggota keluarga yang melakukan peran melihat langsung ketika penderita minum obat sampai tertelan di mulut memiliki kecenderungan 20,250 kali lebih besar berpengaruh terhadap kepatuhan pengobatan penderita TBC dan yang melakukan pendampingan mengambil obat di Fasyankes memiliki kecenderungan 15,000 kali lebih besar berpengaruh terhadap kepatuhan pengobatan penderita TBC serta yang melakukan pendampingan ketika penderita TBC cek ulang dahak di Fasyankes memiliki kecenderungan 11,500 kali lebih besar berpengaruh terhadap kepatuhan pengobatan penderita TBC.

\section{TERIMA KASIH}

1. Kepala Dinas Kesehatan Kabupaten Semarang, JI. MT. Haryono No.29, Kuncen, Ungaran, Kec. Ungaran Tim., Semarang, Telp 024 6923955, email: dinkes@semarangkab.go.id.

2. Kepala Puskesmas Pringapus Kabupaten Semarang, Jl. Hongowicono No. 5, Pringapus, Semarang. Telp 0246924742.

\section{KEPUSTAKAAN}

1. WHO. Global Tuberculosis Report 2018. Switzerland: WHO Press, 2019.

2. WHO. Global Tuberculosis Report 2015. Switzerland: WHO Press, 2016.

3. Nakita. Mencegah Tuberculosis. Retrived Juli, 28, 2017, from Press Reader Web Site: https://www.pressreader.com/indonesia/ nakita/20170322/281509341012879/

4. Sidy Y. N. Pengaruh Peran Pengawas Menelan Obat dari Anggota Keluarga Terhadap Kepatuhan Pengobatan Penderita Tuberkulosis di Kota Pariaman Tahun 2010-2011. Tesis. Depok: Universitas Indonesia, 2012. 
5. PPTI. Buku Saku Perkumpulan Pemberantasan Tuberkulosis Indonesia (PPTI) The Indonesiaan Association Against Tuberculosis. Jakarta: PPTI, 2010.

6. Dinas Kesehatan Provinsi Jawa Tengah. Buku Saku Kesehatan Triwulan 3. Semarang: Dinas Kesehatan Provinsi Jawa Tengah, 2015.

7. Dinas Kesehatan Kabupaten Semarang. Profil kesehatan Tahun 2015. Semarang: Dinas Kesehatan Kabupaten Semarang, 2016.

8. Yoisangadji, A.S., Maramis F. R. R., \& Rumaya A. A.,. Hubungan Antara Pegawas Menelan Obat (PMO) Dan Peran Keluarga Dengan Kepatuhan Minum Obat Pada Pasien Tuberkulosis Di Wilayah Kerja Puskesmas Sario Kota Manado. IImiah Farmasi UNSRAT, 5 (2), 2016.

9. Puskesmas Pringapus. Data Rekam Medis Tuberkulosis. Semarang: Puskesmas Pringapus, 2017.

10. Kementerian Kesehatan RI. TOSS TBC: Temukan TBC Obati Sampai Sembuh. Jakarta: Departemen Kesehatan Republik Indonesia, 2016.

11. Firdaus Kholifatul Ma'arif Zainul. Pengaruh Peranan Pengawas Menelan Obat (PMO) Terhadap Keberhasilan Pengobatan TBC Paru di Wilayah Kerja Puskesmas Baki Sukoharjo. Naskah Publikasi. Surakarta: Universitas Muhammadiyah Surakarta, 2013.

12. Oey, L. Family matters. How patients and treatment supporters experience directly observed TBC treatment in Kota Bogor, Indonesia. The Amsterdam Master's in Medical Anthropology, University of Amsterdam, 2007

13. Kemenkes RI. Pedoman Nasional Pengendalian Tuberkulosis. Jakarta: Departemen Kesehatan Republik Indonesia, 2014.

14. Setiadi. Konsep \& keperawatan keluarga. Yogyakarta: Graha IImu, 2008.

15. Pare L. A., Amiruddin R., \& Leida I. Hubungan Antar Pekerjaan, PMO, Pelayanan Kesehatan, Dukungan Keluarga dan Diskriminasi dengan Perilaku Berobat Pasien Paru. Fakultas
Kesehatan Mayarakat Universitas Hasanuddin, 2012.

16. Limbu R \& Marni. Peran Keluarga Sebagai Pengawas Minum Obat (PMO) dalam Mendukung Proses Pengobatan Penderita TBC Paru Di Wilayah Kerja Puskesmas Baumata Kecamatan Taebenu Kabupaten Kupang. MKM, 02 (01), 2007.

17. Dubale S., Barkesa T., Dereje O. Quality and Treatment Outcomes of Directly Observed Treatment of Short-Course of Tuberculosis (DOTS) in South West Ethiopian: A Cohort Study. Indo American Journal of Pharmaceutical Researc, 2017; 47(2):7703-7710.

18. Khachadourian V., Truzyan N., Hatutyunyan A., Thompson M. E., Harutyunyan T., \& Petrosyan V. Peoplecentered Tuberculosis Care Versus Standard Directly Observed Therapy: Study Protocol for a Cluster Randomized Controlled Trial. BioMed Central, 2015; 16-281.

19. M'Imunya J.M., Kredo T., \& Volmink Jimmy. Patient Education and Counselling for Promoting Adherence to Treatment for Tuberculosis. The Cochrane, 2012

20. Kemenkes RI. Infodatin Tuberkulosis Temukan Obat Sampai Sembuh. Jakarta: Departemen Kesehatan Republik Indonesia, 2015.

21. WHO.Treatment Tuberculosis Guidelines for National Programmes Global. Switzerland: WHO Press, 2003.

22. Kemenkes RI. Startegi Nasional Pengendalian TBC di Indonesia 20102014. Jakarta: Departemen Kesehatan Republik Indonesia, 2011. 